\title{
O papel das instituições na atração de investimento externo: $O$ caso da BMW em Santa Catarina
}

\author{
Laryssa Paola Kobs* \\ Graciella Martignago** \\ Fernando Seabra***
}

\begin{abstract}
Resumo
O objetivo do presente estudo é avaliar a importância de instituições subnacionais na decisão de investimento de uma empresa multinacional. Adota-se, metodologicamente, uma análise qualitativa a partir do estudo de caso do investimento da BMW no estado de Santa Catarina. Com base em entrevistas com pessoas chave no processo decisório, os resultados indicam que as instituições subnacionais foram decisivas na facilitação para superar barreiras ao negócio e na transparência das vantagens do investimento em Santa Catarina
\end{abstract}

Palavras-chave: Investimento direto externo, Instituições, BMW, Santa Catarina

\section{The role of institutions on foreign investment inflows: The caso of BMW in Santa Catarina}

\begin{abstract}
The objective of this paper is to assess the importance of subnational institutions on the decision of a multinational enterprise investment. We follow, in methodological terms, a qualitative analysis to deal with the case study of BMW's investment in the state of Santa Catarina. Based on interviews with some key players to the decision, our results indicate that subnational institutions do matter to decision making process, in terms of facilitating the deal and of emphasizing the advantages to invest in Santa Catarina.
\end{abstract}

Keywords: Foreign direct investment, Institutions, BMW, Santa Catarina

Classificação JEL: F21; F23

\footnotetext{
* Graduada em Relações Internacionais pela Universidade Sul Catarinense (UNISUL). E-mail: laryssakobs@hotmail.com

** Doutora em Administração pela Universidade Federal de Santa Catarina (UFSC) ePprofessora em Negócios Internacionais na Must University, Boca Raton, FL, USA. E-mail: graciellamartignago@gmail.com

***Professor Titular do Departamento de Economia e Relações Internacionais e do Programa de PósGraduação em Relações Internacionais. E-mail: f.seabra@ufsc.br
} 


\section{Introdução}

Nas últimas três décadas, o fluxo de investimentos diretos externos (IDE) avançou, o que fez com que o estoque de IDE como percentual do produto econômico mundial, que era de 10\% em 1990, passasse para 35\% em 2016. Países receptores de investimentos estrangeiros apresentaram crescimento em suas economias e quando as estratégias das empresas investidoras estão alinhadas aos objetivos de desenvolvimento social do país, têm-se impactos significativos provenientes desta relação bilateral, entre investidor e o local (UNCTAD, 2017).

Destaca-se também, que o IDE pode se constituir em importante fonte de inovação tecnológica, expansão da capacidade produtiva, novas técnicas empresariais e administrativas, além de inúmeras outras externalidades que, se concretizadas, impulsionam o crescimento econômico do país receptor (CARMINATI; FERNANDES, 2013).

Entretanto, o fluxo de investimentos externos em ativos fixos parou de crescer em 2020 (UNCTAD, 2020) devido à crise do COVID-19. Acredita-se que em 2020, os fluxos globais de IDE ficaram abaixo de US\$ 1 trilhão pela primeira vez desde 2005 e a UNCTAD (2020) prevê que o IDE diminuirá em mais de 5 a 10 por cento em 2021 e iniciará recuperação somente em 2022. A retração nos fluxos de IDE tiveram impacto, sobretudo, para as economias em desenvolvimento, mais dependentes das cadeias globais de valor (CGV) de indústrias intensivas e extrativas e por serem essas economias menos capazes de implementar as mesmas medidas de apoio econômico que economias desenvolvidas.

De todo modo, acredita-se que a tecnologia, a política e as preocupações com a sustentabilidade constituem tendências multifacetadas e podem gerar diferentes configurações de produção formando trajetórias que dependerão de cada indústria (UNCTAD, 2020). Uma possibilidade é que ocorra um reshoring, levando cadeias de valor a serem mais curtas e menos fragmentadas, com maior nível de concentração geográfica de valor adicionado. Outro fenômeno é a regionalização, que reduzirá o comprimento físico das CGV, mas não a fragmentação da oferta. Os investimentos buscarão eficiência global no mercado regional com investimentos em segmentos verticais de CGV, o que exigirá cooperação econômica regional, política industrial e promoção de investimentos.

Essa nova realidade exigirá uma mudança no paradigma de desenvolvimento de investimento. Para a UNCTAD (2020), a eficiência orientada para a exportação dará lugar a segmentos estreitamente especializados, focados em mercados regionais; a competição baseada em custos dará espaço a investimentos diversificados com base na flexibilidade e os investidores industriais de grande escala com "grande infraestrutura" darão espaço para 
instalações de manufatura em pequena escala e serviços com "infraestrutura enxuta". Portanto, a pandemia gera um novo cenário para políticas de desenvolvimento de investimento, acarretando a necessidade de se reverem as estratégias de promoção de investimento para infraestrutura e serviços.

A produção internacional e a promoção de investimento industrial voltados para a exportação, que caracterizaram os investimentos internacionais nas últimas três décadas, e foram os pilares do desenvolvimento e estratégias de industrialização da maioria dos países em desenvolvimento, com investimentos voltado em explorar fatores de produção, recursos e mão de obra de baixo custo perderão relevância. Um reequilíbrio rumo ao crescimento baseado na demanda interna e regional e nos serviços, com inversão na economia verde e na infraestrutura de serviços, apresentará grande potencial para contribuir no alcance da sustentabilidade. Objetivos de Desenvolvimento Sustentável (ODS) configuram novas perspectivas na definição de estratégias para as políticas de atração de investimentos internacionais (UNCTAD, 2020).

A busca de oportunidades de investimento nos mercados globais estará focada em projetos de criação de valor em infraestrutura, energia renovável, água e saneamento, alimentos e agricultura, e cuidados de saúde (UNCTAD, 2020), o que garantirá a geração de importantes externalidades positivas e fazendo com que muitas instituições locais brasileiras possam desenvolver ações para atração de IDE. Sabe-se que diferentes variáveis de um local, seja município, estado ou país, podem influenciar a atração de investimentos estrangeiros. As questões políticas, sociais e econômicas possuem grande impacto sobre a decisão de investimento externo (AMAL; SEABRA, 2005).

Estudos da área de negócios internacionais e da geografia econômica têm indicado que a atração de IDE pode envolver diferentes atores para o êxito do processo. Apesar das teorias clássicas de negócios internacionais negligenciarem o papel de atores locais para a atração de IDE, estudos empíricos têm reconhecido o papel das instituições subnacionais para abertura do mercado para o investimento direto estrangeiro. Com a expansão do número de multinacionais ao redor do globo, gerada pela internacionalização de empresas pequenas e médias, inclusive empresas born-global, houve a dispersão geográfica dessas empresas. Impulsionadas pelo crescimento do setor de serviços, pela complementariedade da indústria e dos serviços típica da indústria 4.0, essas atividades da cadeia global de valor alteraram o escopo geográfico da globalização e as políticas regionais das instituições subnacionais passam a fazer parte dessa rede de atores globais (IAMMARINO, 2018). Estes passam a ser ativos no processo de internacionalização, com capacidade de moldar a entrada de investimentos e representando um meio facilitador para intermediar o processo entre a empresa e o mercado alvo. 
Nos anos 1990 surgiram os primeiros casos de estruturas locais de internacionalização no Brasil. Governos estaduais e municipais passaram a constituir secretarias específicas para as relações internacionais com o objetivo de incentivar o comércio exterior e investimentos, sobretudo para atração de IDE (VIGEVANI, 2006). Essas estruturas assumiram diversos formatos como secretarias, coordenadorias, assessorias, conselhos, gerências, diretorias ou departamentos e o número de estruturas cresceu na década de 2000, o que configura um fenômeno recente nas relações federativas e paradiplomáticas brasileiras, conforme aponta Junqueira (2015), e poucas pesquisas têm sido oferecidas sobre os mecanismos pelos quais as regiões subnacionais se coordenam com os investimentos das multinacionais dentro do contexto de um único país (MONAGHAN; GUNNIGLE; LAVELLE, 2018).

Como o intuito de contribuir para esse debate, o objetivo desse estudo é mostrar o papel das instituições subnacionais para a atração de investimento direto, em especial a partir do estudo de caso da unidade produtiva da BMW em Santa Catarina. A compreensão do papel de tais atores e o impacto deles no processo de internacionalização têm relevância para as multinacionais e para a criação de políticas públicas, sobretudo em países em desenvolvimento.

Se faz necessário compreender as principais instituições presentes nos países e de que forma elas têm contribuído para facilitar as relações bilaterais e multilaterais, inclusive dos investimentos externos advindos delas. Ao analisar o investimento direto externo da empresa alemã BMW, em Santa Catarina, um dos maiores investimentos estrangeiros realizados no estado em sua história, pretende-se contribuir para uma análise mais ampla das relações e atores envolvidos nos investimentos diretos entre países distintos. Busca-se a compreensão dos vínculos criados entre os agentes envolvidos com a atração do investimento direto externo e os impactos das instituições subnacionais nestas relações no contexto do estado de Santa Catarina.

Destaca-se a relevância da temática para os gestores públicos, que poderão identificar importantes relações para o estabelecimento de estruturas de governança que tenham como objetivo ampliar os investimentos estrangeiros em seus territórios nesse novo contexto póspandemia que será ainda mais desafiador.

\section{Fundamentação teórica}

Diferentes perspectivas teóricas de investimento direto externo (IDE), como as de negócios internacionais, da economia internacional, da economia geográfica e da inovação têm explicado os determinantes do IDE (DUNNING, 1988; 2001; DUNNING; LUNDAN, 2008). Atributos espaciais e ativos específicos de localização são amplamente estudados na 
literatura. O paradigma eclético da produção considera as vantagens da localização como um dos atributos determinantes do IDE. Estas vantagens consistem em acesso a recursos naturais (preço e qualidade), mas também a recursos humanos qualificados, o know-how tecnológico, a infraestrutura, as instituições, etc. O tamanho e as características do mercado, o grau de estabilidade política e econômica, a disponibilidade e custo da infraestrutura, os custos de transporte, o nível da taxa de câmbio, o grau de abertura ao capital estrangeiro, a política comercial, os regimes de incentivos, a política fiscal, entre outros, também podem ser considerados vantagens da localização (DUNNING, 1988).

As instituições têm como características as de serem específicas do contexto e foram incorporadas no paradigma eclético como vantagens de localização por Dunning (2006). Segundo o autor, as instituições afetam a extensão, o conteúdo e a qualidade dos recursos, das capacidades e do mercado, assim como são influenciadas por eles. As instituições e seus mecanismos de execução podem assumir várias formas, como as de ajuste econômico e estabilização, direitos de propriedade privada, direitos de livre iniciativa, de equidade social etc. Podem afetar a oferta e a demanda e, geralmente, atuam na interface das duas ações. Afetam a demanda através de políticas de distribuição de renda, políticas fiscais e monetárias, e afetam a oferta através das leis, dos mecanismos de regulação, da proteção dos direitos de propriedade intelectual etc (DUNNING, 2006).

Sob a perspectiva da firma internacional, cada país é um conjunto de ativos institucionais, tanto formais quanto informais. Os formais aparecem nas leis e regulamentos; na disciplina dos mercados políticos; nos incentivos e padrões baseados em regras, nas sanções, nas penalidades, políticas e na qualidade das organizações públicas; no aprendizado coletivo derivado da formulação e implementação das instituições; nos acordos internacionais (DUNNING, 2006).

Os ativos institucionais informais são os costumes sociais herdados, a tradição; a existência de organizações estrangeiras como instituições que redesenham o quadro institucional original; a presença de características que estimulam a competitividade das instituições como a inovação e o empreendedorismo; a existência de atitudes em relação à mudança e incerteza; o sistema de confiança, as tradições, as manifestações e a participação ativa em organizações de governo; a orientação social/persuasão moral sobre as instituições, organizações e indivíduos (DUNNING, 2006).

Relevante destacar que Dunning (2006) discute as disfunções institucionais expressas na frequência de crimes, na corrupção, nas falhas no sistema de justiça, na ruptura das relações comunitárias/pessoais, na incapacidade do país em lidar com as mudanças tecnológicas ou 
institucionais, na ausência de boas relações inter e intracorporações, assim como nas falhas nas alianças, códigos, na falta de transparência/honestidade etc (MEYER; NGUYEN, 2005; DUNNING, 2006; MONAGHAN; GUNNIGLE; LAVELLE, 2014).

Neste sentido, as instituições têm se mostrado um ator facilitador importante no processo de internacionalização de empresas e os países têm realizado uma maior diversificação dos instrumentos de política governamental para atrair empresas estrangeiras em seus territórios, reduzindo as barreiras à entrada e proporcionando uma ampla gama de incentivos ao investimento. A atração do IDE tem estado no centro das atenções políticas, envolvendo frequentemente vários níveis territoriais de governança (MONAGHAN; GUNNIGLE; LAVELLE, 2014; IAMMARINO, 2018). As políticas públicas de atração de investimentos estão se tornando mais complexas, mais divergentes e incertas (UNCTAD, 2017), e carecem de mais estudos da academia dadas as fartas evidências do impacto desses investimentos nas economias receptoras desse IDE (IAMMARINO, 2018).

Geralmente analisadas em nível nacional, mais recentemente, as instituições passaram a ser consideraras em nível subnacional (BEUGELSDIJK; MCCANN; MUDAMBI, 2010; ALMOND, 2011; CUERVO-CAZURRA, DE HOLAN; SANZ, 2014; CRUZ; FLORIANI; AMAL, 2020). "As instituições subnacionais são atores definidos como o corpo das instituições locais reguladoras e prestadoras de serviços, com o papel de se envolver com as empresas estrangeiras em nível subnacional” (MONAGHAN; GUNNIGLE; LAVELLE, 2014, p. 134) e oferecem todo suporte e atributos locais necessários para o investimento direto externo (CANTWELL; DUNNING; KUNDAN, 2010).

A ação das instituições subnacionais fornece recursos locacionais, relacionais e de conhecimento, tangíveis e intangíveis, tanto diretamente das instituições subnacionais quanto indiretamente, através das relações que as instituições subnacionais mantêm dentro da rede de negócios mais ampla, o que contribui para iniciar, facilitar e acelerar significativamente a inserção da multinacional no país estrangeiro. As instituições subnacionais constituem-se em uma rede que age no processo de entrada no mercado externo e representam um potencial intermediário entre uma empresa internacional e o mercado externo (MONAGHAN; GUNNIGLE; LAVELLE, 2014; 2018; 2020). Portanto, a rede a ser considerada no processo de internacionalização não pode ficar restrita somente às redes de negócios (JOHANSON; VAHLNE, 2009), mas também deve considerar a rede das instituições subnacionais, que agem endogenamente no processo de internacionalização.

Para lidar com a ambiguidade de muitas leis e regulações desenvolvidas em nível nacional, torna-se fundamental o papel das autoridades locais para interpretação e 
implementação dessas regras (MEYER; NGUYEN, 2005). É no nível subnacional que se expressará o refinamento das diferenças regionais e se pode obter evidências mais precisas para a sensibilidade das decisões de IDE para determinantes de localização (ZHOU; DELIOS; YANG, 2002). São as instituições subnacionais que exercem papel importante na inserção do investidor nas redes de relacionamento, moldando as relações entre os atores envolvidos. Contribuem para a redução das incertezas institucionais, na facilitação do estabelecimento e execução de contratos, na redução dos custos de transação (CANTWELL; DUNNING; KUNDAN, 2010).

Constituem-se em instituições subnacionais as agências de desenvolvimento, as instituições educacionais, o governo local (assembleias, autoridades regionais etc), os órgãos comerciais e os órgãos de apoio. Tão importante como as instituições envolvidas em todo processo de um IDE, que agem diretamente na efetivação do investimento, é a ação de instituições que atuam indiretamente, como as instituições educacionais locais, que são capazes de moldar a disponibilidade de recursos que estejam alinhados com as necessidades que o investidor estrangeiro irá demandar, colaborando em termos de mão-de-obra qualificada, iniciativas de pesquisa e gerando desenvolvimento e inovação na região (MONAGHAN; GUNNIGLE; LAVELLE 2014).

\section{Procedimentos Metodológicos}

Optou-se neste trabalho pela realização de uma pesquisa qualitativa, que dá ênfase sobre as qualidades das entidades e sobre os processos e os significados (DENZIN; LINCOLN, 1994) e não com a frequência de um fenômeno em determinado contexto social (TAYLOR; BOGDAN, 1998; PATTON, 2002).

A pesquisa qualitativa, como é essencialmente descritiva, tanto no processo de obtenção de dados, quanto na disseminação de resultados, permitiu a verificação de como os fenômenos se manifestaram ao longo do processo, e a sua compreensão a partir da perspectiva dos participantes. A pesquisa foi indutiva, pois não pretendeu testar teorias, mas desenvolveu observações particulares e, a partir destas, observou se as categorias existentes, e suas relações, explicam a realidade observada (TAYLOR; BOGDAN, 1998). Como explica Godoy (1995), o estudo qualitativo, indutivo, é o mais indicado quando se lida com problemas pouco conhecidos; a pesquisa é de cunho exploratório, tem caráter descritivo, e busca o entendimento do fenômeno como um todo, na sua complexidade. O estudo de um processo construído socialmente implica na necessidade de um enfoque nos significados que os membros da 
organização atribuem à construção e ao entendimento da sua experiência.

A estratégia de pesquisa utilizada foi o estudo de caso. Como indica Yin (2001), o estudo de caso é a estratégia escolhida ao se examinarem acontecimentos contemporâneos e permite ao pesquisador a compreensão do que se passa em uma instância singular. Os estudos de casos simples são adequados, especialmente, ao exame de relações de elementos múltiplos e interdependentes (LERVIK, 2011).

Na pesquisa qualitativa, o caso a ser analisado é definido intencionalmente para que se entenda um fenômeno específico. Esta situação ocorre quando o investigador tem a oportunidade de observar e analisar uma investigação científica previamente não acessível (LERVIK, 2011; YIN, 2001).

Foram coletados dados secundários (especialmente de publicações especializadas), mas principalmente dados primários, coletados por meio de entrevistas semiestruturadas. As entrevistas, em sua maioria, foram realizadas pessoalmente e gravadas, o que facilitou a coleta de dados, pois garantiu maior fluência e o total resgate de informações. As entrevistas foram marcadas com antecedência e tiveram duração máxima de duas horas. Anotações foram realizadas durante a entrevista e, posteriormente, foram transcritas. No total, foram feitas 8 (oito) entrevistas, sendo 6 (seis) delas presenciais, (1) uma via telefone e outra via e-mail. As entrevistas presenciais e via telefone tiveram duração de 7 (sete) horas e 37 (trinta e sete) minutos, no total.

As entrevistas foram realizadas com os executivos envolvidos no processo de atração de investimentos em Santa Catarina. Participaram como entrevistados: Alexandre Salles Steil, Advogado, atuou como representante jurídico do governo do Estado nas negociações para instalação da BMW em Santa Catarina; Amir Hamad, foi consultor do projeto Inova SC que trouxe a fábrica da BMW para o Estado, ex-Diretor de Desenvolvimento Econômico Sustentável de Santa Catarina e ex-Gerente de Relações Governamentais e Sociais da BMW Group no Brasil; André Emiliano Uba, procurador do estado de Santa Catarina, foi designado como Consultor Jurídico da Secretaria de Estado do Desenvolvimento Econômico e Sustentável, prestando consultoria ao estado no projeto que trouxe a BMW para Santa Catarina; Clenilton Carlos Pereira, ex-Vereador e ex- Secretário de Desenvolvimento Econômico da cidade de Araquari. Ao longo das negociações virou Vice-prefeito e, posteriormente, Prefeito da cidade sede da BMW no Brasil; Eduardo Balduíno, foi coordenador de Comunicação Social da Secretaria de Estado do Desenvolvimento Econômico e Sustentável de Santa Catarina e responsável pela assessoria de imprensa do projeto Inova-SC; Guilherme Bez Marques, foi Gerente de Economia Internacional na Secretaria Executiva de Assuntos Internacionais de 
Santa Catarina; Marcelo Fett; Ex-Presidente da Itajaí Participações, atuou na atração de investimentos no Estado de SC; Paulo Bornhausen; ex-Secretário de Estado na Secretaria de Desenvolvimento Econômico Sustentável de Santa Catarina (2011-2014), coordenador da vinda da BMW para o Estado.

Para a análise dos dados, como a realidade estudada é complexa e pouco conhecida, optou-se por partir de perguntas de interesse amplo (GODOY, 2006). Contou-se com uma estrutura teórica de referência, conforme mostra o Quadro 1:

Quadro 1 - Categorias de análise

\begin{tabular}{|l|l|l|}
\hline \multicolumn{1}{|c|}{ Categorias de Análise } & \multicolumn{1}{|c|}{ Descrição } & \multicolumn{1}{|c|}{ Autores } \\
\hline Tipos de instituições & Instituições que compõem a rede & $\begin{array}{l}\text { Johanson e Vahlne (2009) } \\
\text { Monaghan; Gunnigle; Lavelle } \\
\text { (2014); Mudambi; Navarra (2002) }\end{array}$ \\
\hline Papel das instituições & $\begin{array}{l}\text { Tipos de suporte/apoio local; } \\
\text { confiança do Investidor; Incentivos } \\
\text { proporcionados; políticas locais X } \\
\text { centrais; políticas governamentais } \\
\text { de proteção; ativos/infraestrutura e } \\
\text { instituições; }\end{array}$ & $\begin{array}{l}\text { Monaghan; Gunnigle; Lavelle } \\
\text { (2014); North (1990); Cantwell; } \\
\text { Dunning; Lundan (2010); Meyer; } \\
\text { Bevan; Estrin; Meyer (2004); } \\
\text { Dunning (1998; 2001) }\end{array}$ \\
\hline Relevância na rede & $\begin{array}{l}\text { Importância das instituições } \\
\text { subnacionais }\end{array}$ & $\begin{array}{l}\text { Monaghan; Gunnigle; Lavelle } \\
\text { (2014; 2018; 2020) }\end{array}$ \\
\hline Momentos do suporte/apoio & Antes/ depois da entrada do IDE & $\begin{array}{l}\text { North (1990); Monaghan; } \\
\text { Gunnigle; Lavelle (2014; 2018; } \\
\text { 2020) }\end{array}$ \\
\hline
\end{tabular}

Fonte: Elaboração própria.

\section{Investimento Direto Externo em Santa Catarina}

Apesar da intensa concentração de IDE na região sudeste do Brasil, mais especificamente, no estado de São Paulo, notou-se um crescimento razoável nos fluxos de IDE direcionados à região sul do país. Observa-se, no entanto, como apontado por Linhares (2005), que, historicamente, Santa Catarina não se destacava na atração deste investimento; contudo há claros sinais de que essa realidade tem mudado na última década. Existe, porém, dificuldade de dados para aferir essa evolução recente. As bases estatísticas referentes ao acompanhamento dos fluxos (ingresso e saída) de IDE, tanto por estados da federação como por setores de atividade tornaram-se, recentemente, não acessíveis e essa informação de IDE é disponível apenas para o total do país.

A Figura 1 ilustra o fluxo de ingresso de IDE no Brasil no período 2009-2020, indicando que o país registrou rápida expansão na atração de investimentos em 2010/2011, mantendo valores expressivos de ingresso de IDE - entre US\$ 70 e 80 bilhões por ano - até 2019. O efeito 
da pandemia, assim como sobre o crescimento do PIB, foi severo também com a atração de IDE: queda de $50 \%$.

Figura 1 - Fluxo de Ingresso de IDE, Brasil - 2009-2020

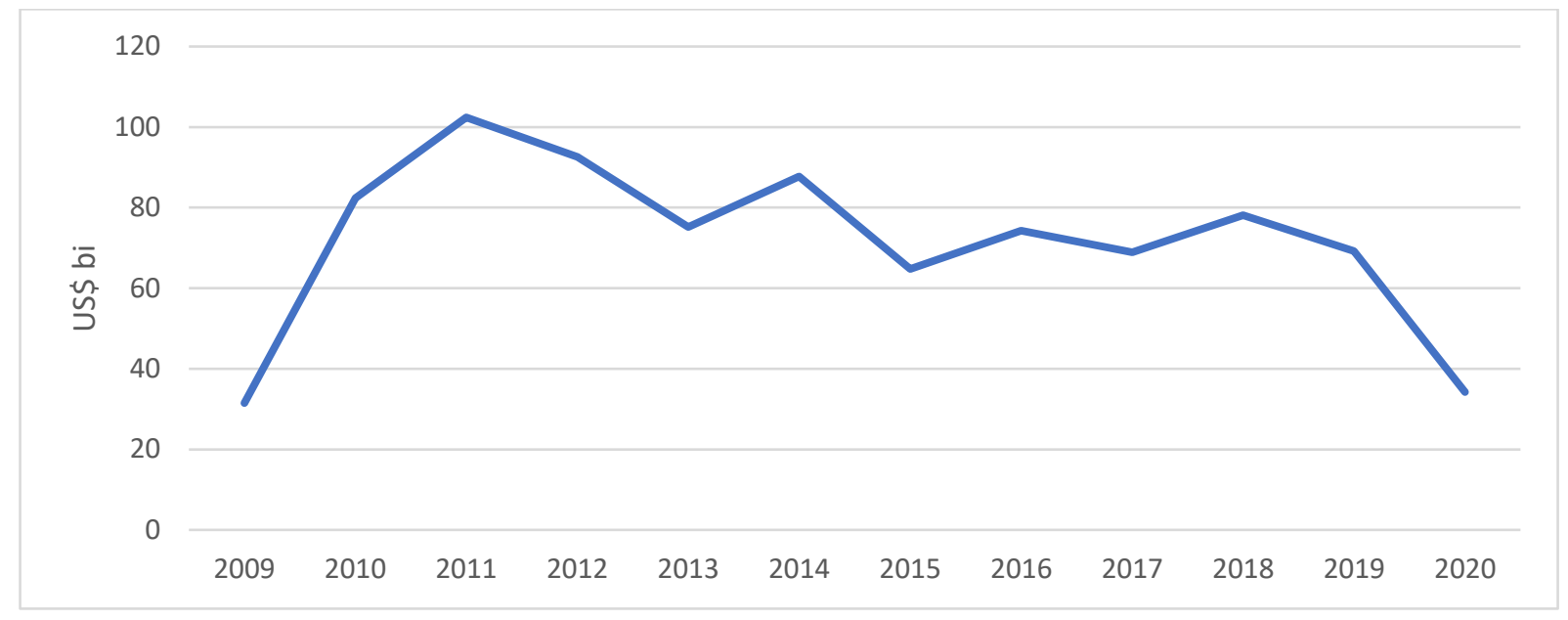

Fonte: Dados brutos: Banco Central do Brasil.

Para os três primeiros trimestres de 2019, a Câmara de Comércio Exterior (CAMEX, do Ministério da Economia) divulgou Boletim de Investimentos Estrangeiros, publicação que acompanhava tendência de ingressos de IDE por país de origem, setores de atividade e estados da federação. Os resultados por estados são divulgados por estado apenas por número de projetos para o segundo e terceiro trimestres de 2019. Com base nessas informações, Santa Catarina teve apenas dois projetos confirmados de IDE (2,8\% do total do país), enquanto os três estados do Sul registraram 8 projetos (ou seja, 11,1\% do total). O mesmo boletim informa em sua primeira edição (1o. trimestre de 2019) o ranking dos estados que atraíram o maior valor de IDE acumulado entre 2003 e 1 o.sem/2019.

$\mathrm{O}$ resultado indica uma significativa semelhança entre os que mais atraem IDE e o tamanho do PIB desses estados: os estados que mais receberam IDE são (em ordem decrescente): São Paulo, Minas Gerais, Rio de Janeiro, Paraná, Rio Grande do Sul e Santa Catarina. Os estados de maior PIB (de acordo com IBGE) são: São Paulo, Minas Gerais, Rio de Janeiro, Rio Grande do Sul, Paraná e Santa Catarina. O estado é o sexto em ambas as listas, o que ratifica uma tendência uniforme em termos de captação de IDE em relação ao PIB para Santa Catarina e os principais estados do país. Esse resultado indica também uma significativa melhora da posição de Santa Catarina no período 2015-2019, uma vez que, segundo Banco do Nordeste (2016), o estado ocupava a 13a. posição na atração de IDE entre 2003-2014, com apenas $2,1 \%$ do ingresso total do país. 
Essa melhor performance de Santa Catarina na captação de IDE é ratificada com base nas informações compiladas pela Rede Nacional de Informações sobre o Investimento (RENAI) do Ministério da Economia. Esses dados de investimentos referem-se a aportes de capitais estrangeiros divulgados por empresas multinacionais como aquelas estabelecidas no país. Desse modo, tais informações são bastante correlacionadas com os dados de fluxo de IDE, embora não sejam exatamente iguais. A Tabela 1 relaciona esses volumes de investimentos anunciados em que houve declaração da unidade da federação.

Os resultados estão compilados para os seis principais estados (por PIB e atração de IDE) e com médias anuais calculadas para dois subperíodos: 2015-2016 e 2017-2019. Pode-se observar que, embora menos que o valor de IDE aportado pelos demais estados, Santa Catarina experimentou o maior crescimento na atração de IDE nos últimos anos da década de 2010, o que corrobora o resultado acima e caracteriza o período em que ocorre a instalação da BMW em Santa Catarina (estudo de caso desta pesquisa).

Tabela 1 - Investimento anunciado no Brasil, por estados selecionados, 2015-2019

\begin{tabular}{|l|c|c|c|}
\hline \multirow{2}{*}{ UF } & \multicolumn{2}{|c|}{$\begin{array}{c}\text { Investimento anunciado (média anual, em US\$ } \\
\text { bilhões) }\end{array}$} \\
\cline { 2 - 4 } & $2015-2016$ & $2017-2019$ & Variação \\
\hline São Paulo & 6,5 & 9,7 & $48 \%$ \\
\hline Minas Gerais & 3,0 & 5,0 & $68 \%$ \\
\hline Rio de Janeiro & 3,7 & 3,2 & $-14 \%$ \\
\hline Paraná & 3,8 & 4,4 & $18 \%$ \\
\hline Rio Grande do Sul & 1,8 & 1,9 & $3 \%$ \\
\hline Santa Catarina & 0,5 & 1,3 & $161 \%$ \\
\hline
\end{tabular}

Fonte: Ministério da Economia (2020).

\section{A decisão de investimento da BMW e as instituições subnacionais em Santa Catarina}

A partir de 1990, a BMW iniciou as atividades no Brasil via importações de carros, mas somente em 1995, estabeleceu-se como uma companhia nacional de vendas e, em 1999, lançou a BMW serviços financeiros. Em 2009, o grupo BMW trouxe a marca MINI para o Brasil e, em 2014, realizou um investimento greenfield e inaugurou uma fábrica de automóveis em Araquari-SC (BMW, 2017; 2020). 
Os investimentos da BMW em Santa Catarina revelaram uma ação estratégica de market seeking. O crescimento do mercado brasileiro do setor automobilístico fez com que a empresa tivesse interesse de aumentar o envolvimento dos seus negócios no Brasil. Em 2012, o Brasil era o quarto mercado do mundo para o setor automobilístico e,

Não teria sentido, estrategicamente para BMW, fazer uma planta em qualquer outro lugar dadas as peculiaridades do Brasil. A BMW veio para o Brasil em um molde diferente, com planta flexível, baixa automatização, alta quantidade de mão-de-obra para atender o mercado local. Então precisava ser instalada no Brasil (entrevistado H).

O estado de Santa Catarina motivou-se a entrar em contato com a montadora alemã devido a uma matéria do Jornal Valor Econômico, do dia 12 de maio de 2011. A matéria revelou o interesse da BMW em abrir sua primeira fábrica na América do Sul. "Sendo assim, a próatividade do Estado foi fundamental para que as negociações entre as partes se iniciassem" (entrevistado B). Segundo o entrevistado, a ideia de que havia outro país "na mira" da empresa, contribuiu para que todas as esferas nacionais (federal e regional) estivessem envolvidas na atração deste investimento. Previamente à definição da empresa, houve contato com instituições nacionais e o papel da política industrial nacionais para o setor automobilístico foi relevante para o investimento.

Nos dois anos de negociação, a BMW não saiu dos jornais. Houve o caso que a assinatura do acordo precisou ser adiada porque dependia da assinatura do programa do Governo Federal, o Inovar Auto, para que a BMW também tivesse os benefícios federais (entrevistado B).

Não sendo o Brasil a única opção na América do Sul, as posições do governo federal tiveram grande relevância. Pós um ano de negociação, em 2012 quaisquer entraves estaduais já estavam, basicamente, quase todos superados. O último ano foi de negociação do governo federal, com a inserção do Inovar- Auto. Os incentivos do governo federal foram determinantes já que existia a opção do México (entrevistado M).

Havia, portanto, uma coordenação de políticas nacionais e regionais para a atração de investimentos. Destaca-se a evidência no sentido de que todos os atores envolvidos atuaram em rede, nos três níveis de governo, federal, estadual e municipal.

\subsection{As instituições estaduais}

A BMW passou a ser contatada como parte de um programa estadual previamente existente no Estado. 
O que poucos sabem é que a BMW fez parte de um programa que já estava sendo desenvolvido dentro do Estado sob a liderança da Secretaria do Desenvolvimento Econômico e Sustentável. O programa se chamava: SC@2022, que previa efeito de longo prazo no seu planejamento e buscava colocar Santa Catarina no rol dos estados que alcançavam desenvolvimento a partir da ciência do conhecimento (entrevistado B).

A Secretaria de Desenvolvimento Econômico Sustentável, responsável pelo planejamento do programa, alcançava três áreas: o desenvolvimento econômico, o meio ambiente e a ciência e tecnologia. "A intenção era unir essas três áreas através de um trabalho convergente" (entrevistado B). O programa SC@2022 apresentava cinco projetos que eram considerados principais dentro do planejamento: o Sinapse da Inovação; os Centros de Design Digital; o Trabalho para Inovação; os Acordos Internacionais Direcionados; e o Inova SC (Governo do Estado de SC, 2011).

Segundo os entrevistados, cada projeto foi desenvolvido com um objetivo. Em especial, o projeto Inova SC teve impacto direto sobre o caso de atração de IDE da BMW. Esse projeto tinha como papel promover a articulação e suporte ao desenvolvimento de polos e distritos de inovação e parques tecnológicos, além de estabelecer estratégias de captação de investimentos e recursos para a área de inovação, gerar cooperação internacional nas áreas acadêmicas, científica, tecnológica e empresarial.

Segundo o entrevistado B:

Para desenvolver a cultura da inovação, fazer Santa Catarina se destacar na indústria do conhecimento, você precisava trazer 'know-how', e trazer para o estado indústrias que já funcionavam, coisas que já tinham no mundo, tanto para que o Estado tivesse o 'know-how', como para ser o embrião. Você não começa do zero, você precisa realmente trazer indústrias de fora. E nesse meio tempo, fazendo isso, buscando, foram trazidos laboratórios farmacêuticos e outros empreendimentos. Nisso apareceu no jornal que a BMW iria implantar uma fábrica na América Latina, e que já estavam na disputa México e São Paulo. Foi aí que o secretário de desenvolvimento econômico da época bateu o pé que iria trazer a BMW pra cá.

Para o entrevistado $\mathrm{S}$,

A ideia era montar, e estão sendo montados no estado, centros de inovação tecnológicos, que servem como polos de agregação de universidades, empresas, de conhecimentos, estudos e da própria incubação de empresas dentro de regiões específicas do estado. E dentro do projeto INOVA uma das atribuições era "vender" Santa Catarina para o Mundo, numa atuação sinérgica com a SCPAR, com Secretaria de Assuntos Internacionais. O que a gente procurava fazer 
era criar portfólios do estado que possibilitasse as empresas saberem das oportunidades de investimentos.

O entrevistado F corrobora que "foi, então, através do Projeto Inova SC que o case da BMW surgiu. O projeto foi o responsável por negociar com a BMW desde o começo das negociações, em maio de 2011, até o anúncio oficial da escolha da BMW por Araquari, em outubro de 2012 " e, por fim, viria a ser tornar um case de sucesso para o planejamento inicial desenvolvido no estado.

As negociações por Santa Catarina para trazer a fábrica da BMW envolveram três secretarias estaduais: a Secretaria de Assuntos Internacionais, a Secretaria do Desenvolvimento Econômico e Sustentável e a Secretaria da Fazenda, além do projeto Inova SC.

Como descreve o entrevistado $\mathrm{S}$,

Tínhamos uma equipe multidisciplinar, pessoas de diversas experiências. Acho que o projeto era muito leve para que você pudesse ter foco efetivamente nas questões estratégicas principais. O olhar do Secretário de Desenvolvimento, que sempre teve uma visão muito focada em atrair investimento externo foi extremamente importante, tanto que se estabeleceram parcerias com a comunidade da Catalunha, com diversos frutos e intercâmbio com empresas da região de Barcelona. Eu diria que o foco era muito consistente na importância de você atrair investimentos e criar, através dessa atração, um ambiente de inovação no estado.

O grupo formado, além contribuir para atração da BMW, dentro do contexto do Inova SC, teve como papel trabalhar para a efetivação de outros investimentos em SC. "Muitos outros investimentos aconteceram no estado durante o período de negociação com a BMW, mas nenhum na complexidade que a BMW trazia. Então, foi necessária uma equipe bem articulada" (entrevistado F). Cada pessoa tinha uma função dentro do projeto e um vínculo com determinada instituição subnacional presente nas negociações.

\subsection{As negociações}

O contato inicial com a BMW aconteceu quando o representante de Santa Catarina, o secretário de desenvolvimento econômico da época, entrou em contato com a empresa e mostrou o interesse do Estado em ter a primeira planta da fábrica da América Latina em Santa Catarina. Foi então que uma comitiva se dirigiu à Alemanha para iniciar as negociações com empresa, a qual viria a perdurar pelos próximos 23 (vinte e três) meses (maio/2011 - protocolo final: abril/2013) (entrevistado M). 
Entre os que fizeram parte da comitiva estavam o Vice-Governador do estado, o Secretário e o Diretor da Secretaria de Desenvolvimento Econômico e Sustentável, e o Secretário Adjunto das Relações Internacionais.

Conforme relata o entrevistado $\mathrm{H}$,

Fizemos a apresentação e ali se definiu que precisaria de uma estrutura específica para atender a BMW. E por que precisaria de uma estrutura específica? Porque as necessidades apresentadas pela BMW, comparadas com outras empresas, foi completamente diferente. A BMW, no processo de implantação, eles fizeram praticamente um processo de compras interno, que hoje eu conheço, mas que é um processo de filtro daquilo que estava sendo oferecido.

O entrevistado B descreve que "foram dois anos de idas e vindas. Há uma grande dificuldade em negociar com os alemães, porque eles têm uma obsessão por detalhes e por perfeição; uma vírgula era discutida durante uma semana".

Diferente de empresas que buscam realizar investimento em outros países/ regiões em troca de incentivos fiscais, a BMW demonstrou desde o começo que isso não seria o bastante para empresas, mas que haveria muitos outros fatores que influenciariam a decisão da montadora. Algo que se alinhava às estratégias de atração de investimentos do estado e que contribuiu para o êxito das negociações.

O caso da BMW mostrou que não havia somente um elemento que iria influenciar na atração da empresa, mas sim um conjunto que seria considerado. O estado não faz leilão fiscal, assim como não doa terrenos. Santa Catarina quer empresas que considere em seu Business Plan tudo que o estado tem para dar, não estando limitada ao incentivo fiscal, pois empresas que buscam somente isso não têm necessariamente o intuito de ficar (entrevistado $\mathrm{M}$ ).

$\mathrm{O}$ entrevistado $\mathrm{H}$ esclareceu a respeito das exigências da montadora no que compete à infraestrutura do estado e mostrou que os incentivos fiscais oferecidos pelo governo não foram decisivos para a definição do local para a instalação da montadora.

Foi diferente de muitas empresas que buscam o governo para receber incentivos. A BMW recebeu o pacote de incentivos, que obviamente eram estabelecidos por lei, mas nas condições mais rápidas e não mais fáceis, porque processos legais foram cumpridos. $\mathrm{O}$ detalhe deste caso é que, atrelados aos benefícios e incentivos, vinha uma série de obrigações de infraestrutura (entrevistado $\mathrm{H}$ ). 
Dentre os demais critérios para a escolha do local, foram considerados o IDH, índices de segurança, questões de logística, a existência de equipes de segurança em menos de cinco minutos da planta, a disponibilidade de atendimento médico em $15 \mathrm{~min}$, um terreno que atendasse as exigências e inúmeras especificidades da fábrica, que constituíam uma série de exigências que iam além de incentivos tributários e, por isso, o governo precisou atuar de forma alinhada com todas as estruturas para que a infraestrutura local atendesse todos os compromissos que estavam envolvidas nas negociações.

Os fatores determinantes para escolha do local de implantação da fábrica envolviam: questões ambientais, geológicas, climatológicas, meteorológicas, disponibilidade e acesso a recursos (água, energia, saúde) e qualidade de vida local.

Dentre os aspectos considerados para a escolha do terreno, segundo os entrevistados e que são padrões globais para todas as fábricas da montadora - estão: abastecimento garantido de energia e água; vias de acesso bem posicionadas (logística); área sem impeditivo ambiental; distância do mar de, pelo menos, $5 \mathrm{~km}$ (sem riscos de tsunami); mão-de-obra qualificada na região; acesso à saúde, com disponibilidade de médicos (especialmente que falem Alemão / Inglês); e escolas básicas internacionais.

Outras questões que podem ter contribuído para a escolha da montadora por Santa Catarina, conforme os entrevistados, são: (i) a pró-atividade do Estado, no posicionamento nas negociações, onde chefes de estado estavam presentes, algo que não aconteceu em São Paulo, por exemplo, explicou o entrevistado M.; (ii) fatores históricos culturais de Santa Catarina, também, contribuíram na escolha da montadora pelo estado:

Os alemães "se sentiram em casa" em Santa Catarina, eles queriam vir para o Estado, desde que, claro, o estado se encaixasse no Business Plan deles. Então, esse critério intuitivo cultural teve grande influência, mas só foi relevante por SC também ter atendido aos outros requisitos necessários (entrevistado $\mathrm{M}$ ).

(iii) ambiente de negócio favorável ao investidor,

A decisão do executivo é o principal fator na decisão de escolha enquanto o incentivo fiscal é a oitava para BMW. Ele se sentir à vontade no ambiente então é primordial para tomada de decisão. Fator segurança, mobilidade, mão-de-obra qualificada, o valor do alemão está implantado na cultura local. (entrevistado $\mathrm{H}$ ).

O entrevistado F complementa afirmando que 
Quanto mais ágil o estado, maior a probabilidade de trazer investimentos - ambiente favorável de negócio é o resumo de tudo, que é a palavra-chave para uma política de atração de investimento, pois há a necessidade de segurança jurídica, luz, gás, estrutura, financiamento. O que define o sucesso de uma política de atração de investimento é o ambiente favorável negócios.

\subsection{O processo de instalação e o papel das instituições}

A planta fabril desenvolvida pela BMW para unidade de Araquari tem como fim a "Fabricação, distribuição, venda, importação, revenda e exportação de automóveis e componentes fabricados pela montadora ou empresas afiliadas" (BMW, 2017). Foram 170 milhões de Euros investidos na construção da unidade de produção, em uma área ocupada de aproximadamente $1,5 \mathrm{mil} \mathrm{m} \mathrm{m}^{2}$, e se esperava gerar 1.100 empregos diretos em um prazo de 5 (cinco) anos. A unidade iniciou com capacidade de produzir 40.000 unidades por ano, além da importação de 5.000 unidades por ano, sujeito a estabelecimento de quotas de importação pelo Governo Federal (Protocolo de intenções).

Para montadora escolher a cidade, no norte de Santa Catarina, houve uma demanda de muito esforço e dedicação para o atendimento das exigências da empresa. "Na BMW não teve isso de deixar algo para fazer depois, não existe. Para a BMW não existe 99\%, lá é 100\%. É certo ou errado, não existe jeitinho de fazer as coisas acontecerem, isso é muito da cultura deles, o alemão", descreve o entrevistado $P$.

Para o prefeito de Araquari, a cidade tinha o que suas concorrentes, durante as negociações, não tinham: um terreno estratégico e com excelente logística, um raio de menos de $100 \mathrm{~km}$ com acesso a 4 (quatro) portos do estado, até mesmo o fato de não haver sindicatos na região, que pudessem então atrapalhar logo de início o trabalho que seria desenvolvido na fábrica (entrevistado $\mathrm{P})$.

O entrevistado $\mathrm{M}$ complementou afirmando que a localização do terreno, localizado na BR-101, atendia os aspectos logísticos, além de que o gás passava na frente do terreno e Araquari não apresentava um IDH alto, o que permitia o estado oferecer incentivo atrativo. Destaca o esforço da estrutura organizacional para a atração da BMW, conforme relato.

Se não fosse a estrutura formada para atração da BMW ela não teria vindo. Eu devo ter ido à Florianópolis com nossa equipe (Fundema, planejamento, desenvolvimento) próximo de umas 100 vezes, toda semana a gente estava lá, às vezes duas/ três vezes. O esforço e a prioridade dadas as questões que eram exigidas e estavam em nosso 
domínio foram fundamentais para que Araquari chegasse aonde chegou (entrevistado M).

Para o líder do projeto, o entrevistado B,

O principal fator para BMW estar em Santa Catarina, nas palavras da Sra Gleide Souza, executiva chefe do projeto pela BMW Brasil, foi a nossa decisão de ter escolhido a empresa para estar aqui. Essa determinação, aliada a equipe se altíssimo nível montada pelo GESC e as boas condições econômicas, técnicas e sociais do nosso estado fizeram a diferença.

A Figura 2 sinaliza a rede de instituições subnacionais que atuaram na atração do IDE da BMW para Santa Catarina.

Figura 2 - Rede de instituições subnacionais para atração de IDE em SC

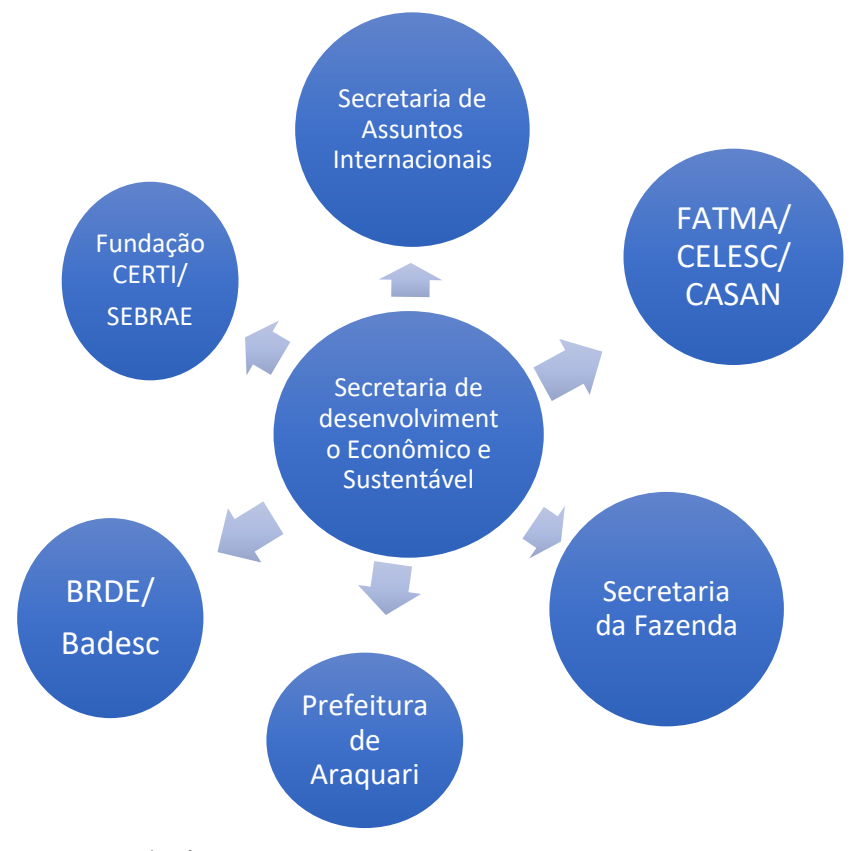

Fonte: Elaboração própria.

O Quadro 2 descreve o processo de implantação da BMW em Araquari. Nesse quadro, constam informações desde o início das tratativas, 2011, passando pelo lançamento da pedra fundamental da fábrica em 2013, até a produção efetiva de veículo, em 2014, que segue em 2015. 
Quadro 2 - Processo de instalação da fábrica BMW em Araquari

\begin{tabular}{|c|c|}
\hline 2011 & Maio: Início das negociações com a BMW \\
\hline 2012 & $\begin{array}{l}\text { Outubro: O BMW Group Brasil anuncia oficialmente, no Salão do Automóvel, a } \\
\text { construção de sua fábrica de automóveis no país }\end{array}$ \\
\hline 2013 & $\begin{array}{l}\text { Maio: Início da preparação do terreno da fábrica (terraplenagem) e do Centro de } \\
\text { Treinamento em Joinville. } \\
\text { - 500.000m² de área compactada e elevada a } 3 \text { metros. } \\
\text { - Realocação de linha de transmissão de alta tensão para próximo à fábrica. } \\
\text { Novembro: Início da construção da fábrica, a } 30^{\mathrm{a}} \text { unidade fabril do BMW Group } \\
\text { no mundo e a primeira na América do Sul. } \\
\text { Dezembro: Evento para o lançamento da pedra fundamental. Presentes: Vice- } \\
\text { Presidente da República, Michel Temer; o Governador de Santa Catarina, } \\
\text { Raimundo Colombo; o CEO para as Américas da BMW: Ludwig Willish; o } \\
\text { Presidente da BMW Brasil, Arturo Piñeiro e o Vice-Presidente de Manufatura, } \\
\text { Gerald Degen, responsável pela Fábrica da BMW em Araquari. }\end{array}$ \\
\hline 2014 & $\begin{array}{l}\text { Setembro: Início da produção com as tecnologias de logística e montagem, além } \\
\text { das áreas de laboratório e qualidade. } \\
\text { O BMW Série 3, um dos veículos de luxo de maior sucesso no mundo, é o primeiro } \\
\text { modelo da marca a ser fabricado em solo brasileiro. } \\
\text { Novembro: O primeiro BMW X1 é fabricado, nas versões X1 sDrive20i, X1 } \\
\text { sDrive20 GP e X1 sDrive 20i GP Teto. }\end{array}$ \\
\hline 2015 & $\begin{array}{l}\text { Fevereiro: Produção do BMW Série 1, com os modelos BMW 120i ActiveFlex } \\
\text { (versões Sport e Sport GP) e BMW 125i M Sport ActiveFlex. } \\
\text { Março: A nova geração do BMW X1 começa a ser fabricada no Brasil. O SAV } \\
\text { (Sport Activity Vehicle) com motor ActiveFlex, desenvolvido parcialmente no } \\
\text { Brasil, com motor movido à etanol. } \\
\text { Abril: Início da exportação para os Estados Unidos. } \\
\text { Junho: Exportação do BMW X1 para os Estados Unidos. } 10 \text { unidades do novo } \\
\text { BMW X1 ao mercado norte-americano. } \\
\text { Agosto: Produção do BMW X3. O versátil SAV é fabricado nas versões X3 } \\
\text { xDrive20i, X3 xDrive20i X Line e X3 xDrive35i M Sport. } \\
\text { Setembro: Início das operações das tecnologias de carroceria/soldagem e pintura. } \\
\text { Fábrica completa, com capacidade de produzir } 32 \text { mil carros/ano. } \\
\text { Outubro: Produção do MINI countryman (Cooper S Top e Cooper S All4) }\end{array}$ \\
\hline
\end{tabular}

Fonte: BMW, 2017. Elaboração própria.

Sobre a atuação do governo local, o entrevistado $\mathrm{H}$ enfatiza que "cada governo trabalha de forma diferente a atração de investimentos externos, estando muito voltado aos objetivos e prioridades do governador eleito" (entrevistado $\mathrm{H}$ ).

As secretarias de Assuntos Internacionais e do Desenvolvimento Econômico e Sustentável são órgãos de apoio de um estado e podem contribuir para atração do IDE para região. No estado de Santa Catarina, instituições educacionais como, a Universidade Federal de Santa Catarina (UFSC), Universidade do Estado de Santa Catarina (UDESC), SEBRAE, Serviço Nacional de Aprendizagem Industrial (SENAI), Universidade do Sul de Santa Catarina (UNISUL) são exemplos de instituições que contribuem para o desenvolvimento da mão de 
obra capacitada do estado. Instituições como a Fundação do Meio Ambiente (FATMA), a Companhia Catarinense de Água e Esgoto (CASAN), as Centrais Elétricas de Santa Catarina (CELESC), o Banco de Desenvolvimento da Região Sul (BRDE), a Federação das Indústrias de Santa Catarina (FIESC) e a Fundação Certi foram suporte às demandas requeridas para a atração de IDE e formou-se, então, uma rede de instituições subnacionais.

Tendo em vista as relações estabelecidas desde o começo das negociações com a BMW, a Secretaria de Desenvolvimento Econômico e Sustentável e a Secretaria de Assuntos Internacionais foram as instituições que tiveram papel de maior relevância no processo de atração da montadora.

Segundo o entrevistado $S$,

Havia a Secretaria de estado que era o elo de ligação com os demais órgãos públicos, você tinha que ter uma interação com a secretaria da fazenda em razão de precisar criar um regime especial para BMW, um regime especial fiscal e você tinha também essa interlocução com a SCPar e com a Secretaria de Assuntos Internacionais, que também, dentro de suas áreas, faziam parte desse grande esforço de atração de novas empresas para SC.

A Secretaria de Desenvolvimento Econômico e Sustentável, portanto, foi a responsável por montar a equipe e aproximar instituições e pessoas.

Sem dúvida alguma, a instituição que fez diferença no processo foi a equipe que a secretaria de desenvolvimento montou, que tinha o consultor jurídico que foi fundamental no aspecto legal, como procurador do estado. Ele e o outro advogado constitucionalista, juntos, eles fizeram todo arcabouço legal da operação e discutiram com os alemães. Na área do meio ambiente, o diretor do meio ambiente da Secretaria possuía grande conhecimento na área. Outro membro da equipe era um advogado imobiliário, que desenvolveu todo modelo do centro de inovação e havia outro membro que tinha conhecimento em comércio internacional porque sempre trabalhou nessa área (entrevistado B).

O BRDE foi o responsável pelo empréstimo de cerca de $\mathrm{R} \$ 240$ milhões a BMW, maior valor já emprestado pela instituição financeira a uma empresa (Entrevistado M). Centros tecnológicos, como a Associação Catarinense de Tecnologia - ACATE e Sapiens Park, e, também, a Fundação CERTI, apresentaram relevante papel na atração desse IDE, pois faziam parte do projeto da SDS e estavam no contexto do objetivo de desenvolvimento da tecnologia do plano SC@2022.

Como apresentou o entrevistado $\mathrm{S}$, 
CERTI foi contratada pela SDS para desenvolver o projeto de atração de investimentos e de construção de parques tecnológicos. A ideia era montar, e estão sendo montados no estado, centros de inovação tecnológicos, que servem como polos de agregação de universidades, empresas, de conhecimentos, estudos e da própria incubação de empresas dentro de regiões específicas do estado.

Destacam-se, portanto, as seguintes papeis das instituições subnacionais no investimento direto da BMW em Santa Catarina:

Quadro 3 - Instituições envolvidas no Case BMW

\begin{tabular}{|c|c|}
\hline Instituição & Papel \\
\hline $\begin{array}{c}\text { Governador e Vice-Governador } \\
\text { do Estado }\end{array}$ & $\begin{array}{c}\text { Apoio institucional/ suporte junto ao governo } \\
\text { federal. Legitimidade. }\end{array}$ \\
\hline Secretaria de Desenvolvimento Econômico & $\begin{array}{c}\text { Coordenação da rede, articulação com demais } \\
\text { instituiçôes; definição de política estadual de } \\
\text { investimentos. }\end{array}$ \\
\hline Secretaria de Assuntos Internacionais & $\begin{array}{c}\text { Assistência e suporte à empresa. Formalização de } \\
\text { acordos internacionais. }\end{array}$ \\
\hline Prefeitura de Araquari & Exigências referentes ao terreno e licenças. \\
\hline FATMA & Licenciamento ambiental \\
\hline Instituições Educacionais e de Tecnologia & Capacitação da mão-de-obra \\
\hline Secretaria da Fazenda & Modelo de incentivos fiscais \\
\hline BRDE & Financiamento do investimento da BMW \\
\hline Outras Instituições (CASAN, CELESC) & Infraestrutura para a instalação fabril \\
\hline
\end{tabular}

Fonte: Entrevistas. Elaboração própria.

Conforme Monaghan, Gunnigle e Lavelle (2014), há sempre instituições chaves que estão envolvidas desde o estágio inicial da internacionalização, sendo responsáveis pelo conhecimento das oportunidades existentes ao investidor. Dentro no processo que envolveu a vinda da BMW para Santa Catarina, as instituições que lideraram o processo de atração do investimento foram a Secretaria de Desenvolvimento Econômico e Sustentável e a Secretaria de Assuntos Internacionais. Foram as instâncias administrativas que reconheceram a oportunidade e formaram uma estrutura com dinamicidade capaz de atender as necessidades da montadora. Formou-se uma estrutura capaz de dar o apoio necessário ao investidor durante todo processo de negociação e instalação no mercado.

Destaca-se também que a importância da construção da confiança e o comprometimento junto ao investidor. Algo que pode envolver o início de um novo relacionamento ou desenvolver 
relações já existentes que podem ser estrategicamente importantes. No caso da BMW, as instituições chaves tiveram importante papel na construção da confiança junta à empresa.

Para o entrevistado M, dois fatores que foram importantes para esta confiança:

A BMW entendia a necessidade da presença na América Latina, apesar da instabilidade (política e econômica) da região. Ela apostou no mercado nacional e na região [...] e observou que o governo de Santa Catarina cumpre os acordos. Quando o governo oferece algo, as empresas sabem que o estado irá cumprir, sabem através da experiência tida pelas outras empresas, e dos feedbacks dados por estas. (Algo que aconteceu com a BMW, o governo é ciente de que a empresa conversou com outras empresas). Esta política de cumprir acordo é uma política de estado e não de governo, os incentivos são leis e não promessas. Há comitês para aprovação dos incentivos, não um comitê de governo, portanto, não pode ser revogado no governo seguinte. Há uma previsibilidade, da qual as empresas sabem que estão lidando com um estado que irá cumprir com os compromissos. O que traz a estabilidade para as empresas.

De acordo com o entrevistado $\mathrm{H}$, a construção da confiança se deu,

Pelo profissionalismo de ambas as partes. O que foi prometido foi acordado, e o que não prometido ou acordado é sentado na mesa para resolver os próximos passos. Não houve em nenhum momento "um ganha, perde", sempre ambas as partes ganharam. Hoje a BMW é o maior importador do estado. Já gerou centenas de milhões de reais de ICMS para o governo. "Crescemos juntos". Há muita transparência. No protocolo de intenções assinado entre as partes prevê as conversas para resolução de qualquer empecilho que possa surgir.

Dentro do processo de atração da fábrica da BMW para Santa Catarina, o papel do governo local foi fundamental, como no caso que envolveu a resolução do Inovar Auto junto ao governo federal. Para o entrevistado F, a relação do governo de Santa Catarina com o governo federal foi

Conflituosa em dado momento, devido à política de componente nacional estabelecida pelo governo federal para as indústrias, e pelo aumento do IPI. O governo do estado fez propostas de escalonamento sobre o Inovar Auto, foi determinado um tempo para adaptação das indústrias que estavam se instalando no país para preenchimento dos $65 \%$ de componentes nacionais. Foi uma demanda do estado devido à negociação com a BMW que permitiu que a empresa não descartasse a vinda para o Brasil [...] É fundamental que exista um alinhamento entre governo do estado e o governo federal, porque ao analisar a matriz decisória que envolve a escolha do local para investimento, grande parte dela compete ao poder federal, uma menor que compete ao estado e uma pequena parcela ao munícipio. Então, se não tiver um 
alinhamento, pelo menos, entre o estado e o governo federal, fica inviável.

Segundo Bevan, Estrin e Meyer (2004), os incentivos criados pelas instituições favorecem o desenvolvimento de acordos com as empresas, para que assim seja possível evitar os limites impostos pelas leis nacionais e, também, colher os benefícios que as leis são capazes de promover. No caso BMW não foi diferente, a empresa e o estado de Santa Catarina firmaram acordos que estabeleciam os deveres e direitos das partes envolvidas e o comprometimento com o que já havia sido tratado.

Segundo o advogado entrevistado S,

Memorandos de entendimento, meu relacionamento foi direto com a BMW, com os técnicos, tanto os alemães como os representantes brasileiros. Havia acordos de confidencialidades, bilaterais, mas o documento básico foi o memorando de entendimento, justamente porque ao estado cabia a ajuda da escolha do terreno, terraplanagem para garantia da qualidade, e o resto o conjunto de diversas exigências feitas pela BMW.

Os memorandos de entendimento, ou também chamado, protocolos de intenção, representam o compromisso do estado para com a empresa, contribuindo para que as partes possam colher os benefícios das negociações e ter ciência de suas obrigações.

Para Cantwell, Dunning e Lundan (2010), as instituições subnacionais oferecem suporte e atributos locais necessários para o investimento direto externo, o que envolve desde o suporte inicial até o pós-entrada. A relação da BMW com Santa Catarina envolveu, desde o início, comprometimento e disposição do estado para atender as exigências da empresa. Sobre a relação entre as partes nesse pós-entrada, segundo o entrevistado $\mathrm{H}$,

Ficaram algumas pendências, pois alguns aspectos são mais difíceis de serem resolvidos. Mas a relação é excelente, ambos os lados compreendem os pontos que estão envolvidos. Nunca foram necessárias cobranças que envolvessem a análise dos protocolos assinados. Tudo é conversado e analisado.

Desta forma, depreende-se que o papel das instituições subnacionais de Santa Catarina foi fundamental para escolha do estado como sede da primeira fábrica da montadora alemã, fato que pode ser notado no desenrolar do processo de atração, e mostra o impacto que uma instituição bem estruturada tem para a atração do IDE para uma região. 


\section{Considerações finais}

O processo de internacionalização das empresas é uma realidade cada vez mais presente nas organizações que visam crescimento e o alcance de novos mercados. A opção pelo investimento direto externo (IDE), por conseguinte, tem se mostrado como uma opção efetiva para as empresas que buscam expandir sua cadeia produtiva e desenvolver um relacionamento de longo prazo em outro país/região.

Um ambiente favorável aos negócios, que apresenta relativa estabilidade econômica e oportunidades ao investidor, contribui para atração do investimento estrangeiro; no entanto, não é o único fator decisório relevante neste processo, que tem se mostrado suscetível ao suporte obtido nesta busca por novos mercados.

A presença de instituições subnacionais bem estruturadas e conscientes do seu papel na atração de IDE reflete um ambiente propício para receber este tipo de investimento e, consequentemente, mais favorável ao investidor. As instituições subnacionais ligadas ao governo são as que apresentam maior impacto na entrada do investimento estrangeiro, pois estão próximas àqueles que possuem o poder de decisão em uma região e são responsáveis pela estrutura que será necessária ao investidor, seja relacionada aos tributos ou suporte para conhecimento do ambiente local.

Como pôde ser observado neste estudo, o estado de Santa Catarina, embora possua ainda uma participação relativamente baixa na atração de IDE, tem experimentado um aumento desse market-share na última década. É nesse contexto que se encontra a decisão do investimento da BMW em Santa Catarina.

Um dos principais resultados obtidos foi a comprovação do papel das agências de desenvolvimento e atração de investimento. Neste sentido, a estrutura da equipe que estava formada, quando surgiu o caso BMW, demonstrou ganhos de eficiência que podem ter sido essenciais para a atração do investimento. A complexidade da negociação exigiu uma ação de coordenação da Secretaria de Desenvolvimento Econômico Sustentável da época, que, de modo coincidente - mas coadunado com as prioridades de governo e das instituições de ensino e tecnologia - buscava por empreendimentos impactantes no ambiente de inovação do estado.

A BMW, como citada pelo próprio coordenador do projeto, foi escolhida pelo estado, e esforços foram desdobrados para que Santa Catarina fosse escolhida pela montadora como sede de sua primeira fábrica na América Latina.

Ao analisar as estratégias e esforços despendidos neste empreendimento é possível observar que secretarias, como a de assuntos internacionais e de desenvolvimento econômico 
e sustentável, foram as instituições chave em todo processo, justamente pelo comprometimento e pró-atividade destas. A liderança da Secretaria de Desenvolvimento Econômico Sustentável no contexto de uma rede de integração de iniciativas de financiamento, incentivos e transparência de inocência fiscal, infraestrutura e qualificação de recursos humanos, foi responsável por criar uma estrutura favorável à atração de investimentos com um evidente viés para setores de tecnologia e inovação.

\section{Referências}

ALMOND, P. The sub-national embeddedness of international HRM. Human Relations, v. 64, 531-551, abr. 2011.

AMAL, M.; SEABRA, F. Determinantes do investimento direto externo (IDE) na América Latina: uma perspectiva institucional. Anpec, 2005. Disponível em: <http://www.anpec.org.br/encontro2005/artigos/A05A076.pdf>. Acesso em: 19 nov. 2016.

BMW. Institucional. Disponível em: http://www.bmw.com.br/pt/fastlane/recursoshumanos.html. Acesso em: 2017.

BMW. BMW no Brasil. Disponível em https://www.bmw.com.br/pt/topics/fascinationbmw/fabrica/fabrica.html. Acesso em: 2020.

BEUGELSDIJK, S.; MCCANN, P.; MUDAMBI, R. Place, space and organization- economic geography and the multinational enterprise. Journal of Economic Geography, v.10, 2010, p. 485-493.

BEVAN, A.; ESTRIN, S.; MEYER, K. Foreign investment location and institutional development in transition economies. Internation Business Review, Vol 13(1), 2004, p. 4364.

CANTWELL, J.; DUNNING, J.; LUNDAN, S. An evolutionary approach to understanding international business activity: The co-evolution of MNEs and the institutional environment. Journal of International Business Studies, v. 41, 567-586, 2010.

CANTWELL; J MUDAMBI, R. Physical attraction and the geography of knowledge sourcing in multinational enterprise. Global Strategy Journal, 1(3-4): 206-232, nov. 2011.

CARMINATTI, J.; FERNANDES, E. Impacto do investimento direto estrangeiro no crescimento da economia brasileira. Planejamento e políticas públicas, n. 41, 2013.

CRUZ, C.; FLORIANI, D.; AMAL, M. The OLI paradigm as a comprehensive modelo of FDI determinants: a sub-national approach. International Journal of Emerging Markets, 2020.

CUERVO-CAZURRA, A.; HOLAN, P. M.; SANZ, L. Location advantage: emergent and guided co-evolutions. Journal of Business Research, v. 67, 508-515, abr. 2014.

DENZIN, N.K.; LINCOLN, Y.S. Handbook of qualitative research. Londres, 1994. 
DUNNING, J. H. The eclectic (OLI) paradigm of international production: past, present and future. International Journal of the Economics of Business, 173-190, 2001.

DUNNING, J. H. The theory of international production. The International Trade Journal, v. 3, n. 1, 21-66, set. 1988.

DUNNING, J. H. Towards a new paradigm of development: implications for the determinants of international business. Transnational Corporations, 15, 173-227, 2006.

DUNNING, J. H.; LUNDAN, S. Institutions and the OLI paradigm of the multinational enterprise. Asia Pacific Journal of Management, v. 25, 573-593, 2008.

ESCRITÓRIO TÉCNICO DE ESTUDOS ECONÔMICOS DO NORDESTE - ETENE. Investimento direto estrangeiro nos estados do Brasil. Banco do Nordeste, 2016. Obtido em:https://www.bnb.gov.br/documents/80223/1103955/Informe+ETENE+N\%C2\%BA+1.pdf /61355d9b-19e3-d420-06a1-c2a487b6014d. Acesso em: 2021.

GODOY, S. A. Introdução à pesquisa qualitativa e suas possibilidades. Revista de Administração de Empresas, São Paulo, v. 35, n. 2, mar/ abr. 1995.

IAMMARINO, S. FDI and regional development policy. Journal of International Business Policy, v. 1, 157-187, dez. 2018.

JOHANSON; J. VAHLNE, J. The Uppsala internationalization process model revisited: From liability of foreignness to liability of outsidership. Journal of International Business Studies, 2009, p. 1411-1431.

JUNQUEIRA, C. G. A. Criação das Secretarias Municipais de Relações Internacionais (Smris) como nova realidade da inserção internacional dos entes subnacionais brasileiros. Boletim de Economia e Política Internacional, n. 21, set.-dez. 2015.

LERVIK, J. E. B. The single MNC as a research Site. Rethinking the case study in International Business and Management Research, 229-250, 2011.

LINHARES, I. J. Potencial de atração do estado de Santa Catarina frente ao investimento direto externo. 71 f. TCC (Graduação) - Curso de Ciências Econômicas, Centro Sócio Econômico, Universidade Federal de Santa Catarina, Florianópolis, 2005.

MEYER, K. E; NGUYEN, H. V; Foreign investimento strategies and subnational instituitions in emerging markets: evidence from Vietnam”. Journal of Management Studies, 42, 2005, p. 63-93.

MONAGHAN, S.; GUNNIGLE, P.; LAVELLE, J. Courting the multinational: subnational institutional capacity and foreign market insidership. Journal of International Business Studies, vol. 45, 2014, p. 131-150.

MONAGHAN, S.; GUNNIGLE, P.; LAVELLE, J. Firm-location dynamics and subnational institutions: creating a framework for collocation advantages. creating a framework for collocation advantages, Industry and Innovation, 25:3, 2018, p. 242-263. 
MONAGHAN, S.; GUNNIGLE, P.; LAVELLE, J. Subnational location capital: the role of subnational actors and socio-spatial factors on firm location. British Journal of Management, Vol 31, 2020, p. 618-635.

MUDAMBI, R.; NAVARRA, P. Institutions and International Business: a theoretical overview. International Business Review, vol. 11, 2002, p. 635-646.

NORTH, D. C; 1990. Institutions, institutional change and economic performance. Cambridge: Cambridge University Press.

PATTON, M. Q. Qualitative research and evaluation methods, $3^{\text {rd }}$ edn. Thousand Oaks, CA and London: Sage, 2002.

REDE NACIONAL DE INFORMAÇÕES SOBRE INVESTIMENTO - RENAI. Panorama de anúncios de investimentos no Brasil, 2019. Brasília: Ministério da Economia, 2020. Obtido em: https://www.gov.br/produtividade-e-comercio-exterior/pt-

br/images/REPOSITORIO/sdci/decoi/cgpi/renai/09032018/Anuncios/PANORAMAa_DEa_A NNUNCIOSa_DEa_INVESTIMENTOSa_2019.pdf. Acesso em: 2021.

TAYLOR, S. B; BOGDAN, E. Introducción a los métodos cualitativos de investigación. Buenos Aires, 1998.

UNITED NATIONS CONFERENCE ON TRADE AND DEVELOPMENT - UNCTAD. World Investment Report 2017. UNCTAD, 2017. Obtido em: https://unctad.org/webflyer/world-investment-report-2017. Acesso em: 2021.

UNITED NATIONS CONFERENCE ON TRADE AND DEVELOPMENT - UNCTAD. World Investment Report 2020. UNCTAD, 2020. Obtido em: https://unctad.org/system/files/official-document/wir2020_en.pdf. Acesso em: 2021.

VAN MAANEN, J. Qualitative Methods Reclaimed. Alfred P. Sloan School of Management, jul. 1983.

VIGEVANI, T. Problemas para a atividade internacional das unidades subnacionais: estados e municípios brasileiros. Revista Brasileira de Ciências Sociais, v. 21, n. 62, 127-139, São Paulo, 2006.

WELCH, D; WELCH, L; MARSCHAN-PIEKKARI, R. Speaking in tongues: language and international management. International Studies of Management \& Organization, v. 35, 10-27, 2005.

YIN, K. R. Estudo de caso: planejamento e métodos. 2. ed. São Paulo: Bookman, 2001.

ZHOU, C.; DELIOS, A.; YANG, J. Y. Locational determinants of japanese foreign direct investment in China. Asia Pacific Journal of Management, v. 19, 63-86, mar. 2002. 